\title{
A Study to Assess Relationship between Different Obesity Indices and Musculoskeletal Discomfort Score in Agricultural Workers in Southern Districts of West Bengal, India
}

\author{
Ayan Chatterjee $^{1,2}$, Sandipan Chatterjee ${ }^{1}$, Neepa Banerjee ${ }^{1}$ and Shankarashis Mukherjee ${ }^{1,3 *}$ \\ ${ }^{1}$ Human Performance Analytics and Facilitation Unit, Department of Physiology, University Colleges of Science and Technology, India \\ ${ }^{2}$ Assistant Professor, Faculty of Allied Health Sciences, ICFAI University, India \\ ${ }^{3}$ Public Health Analytics Group, Department of Food and Nutrition, West Bengal State University, India
}

*Corresponding author: Shankarashis Mukherjee, Public Health Analytics Group, Department of Food and Nutrition, West Bengal State University, Kolkata, 700126, India

\begin{abstract}
Occupation is an important determinant of health in general and its overall positive or negative effect on well-being results from the interaction between individual characteristics and work-related features, the latter comprising biomechanical, psychosocial, and sociological axes. In India, about three fourth of the population are dependent on different type of crop cultivation; of which paddy cultivation is an important one. Paddy cultivation involves in various processes, some of the postures, which were taken by crop cultivators, were very harmful. Some of the works are dominated by static muscular contraction and some other works are involved with repeated dynamic activity. In this backdrop, the present study has been undertaken to assess the relationship between works related musculoskeletal discomforts score and obesity indices among the human resources engaged in paddy cultivation task. Significant association was observed between obesity indices and MSD discomfort score.
\end{abstract}

Keywords: MSD; Agriculture; Obesity; Job demand; Paddy cultivation

\section{Introduction}

Rice is one of the major food crops of the world. It provides the bulk of daily calories; moreover, rice is also one of food which is considered to be a potential food vehicle for the fortification of micronutrients because of its regularly consumption. It is a good source of thiamine (vitamin B1), riboflavin (vitamin B2) and niacin (vitamin B3). The nutrients content of rice was varies depending on the variety of rice soil, and the conditions they growth. On the other hand, rice cultivation is an important sector of earning opportunity for the human resources engaged in agricultural task; $58.4 \%$ of the human resources are engaged in the different agricultural task during the paddy cultivating time in India. And $43.5 \%$ of male and $46.3 \%$ of the female human resources are engaged in different agricultural work during the paddy cultivating time in WB. The area under paddy cultivation is about 44.79 million hectares, the largest in the world. Yet, the agricultural sector in the rural villages of India is still dependent on non-mechanized technique i.e. dependent on the physical effort of the human resources involved [1-4].

During the paddy cultivating time the agricultural workers has to carry out different tasks-ploughing, transplanting, reaping, threshing, and parboiling throughout the year even in a single day too. Earlier studies report that, drudgery is generally conceived as physical and mental strain, agony, monotony, and hardship experienced by human beings [5-8]. While all these results in decline in living and working conditions affecting men and women [9-15]. Therefore, in order to ensure health, wellbeing and thereby improving the work performance, the assessment of occupational health status is considered as an essential factor for the human resources engaged in outdoor occupations especially those who are engaged in different types of tasks during the period of paddy cultivating time [16-22]. 
Paddy cultivation involves in various processes, some of the postures, which were taken by the food growers were very harmful. Some of the works are dominated by static muscular contraction and some other works are involved with repeated dynamic activity [23-24]. According to public health perspective, effective well-documented initiatives for reducing body weight, improving physical capacity, and reducing musculoskeletal pain among health care workers are therefore required. Moreover, there is lack of evidence about the association between body weight status and musculoskeletal injury in different body regions. In this backdrop the present study aims to assess the relationship between different obesity indices and musculoskeletal discomfort score in human resources occupationally engaged in agricultural task especially paddy cultivating task.

\section{Materials and Methods}

Human resources engaged in paddy cultivation, with no known chronic disease history (self-reported) and having a minimum working experience of three years, regularly working on an average for at least a period of six to six and half hours in the agricultural field in Arambagh subdivision in the district Hooghly [(latitude $\left(23^{\circ} 01^{\prime} \mathrm{N}\right.$ to $\left.22^{0} 39^{\prime} \mathrm{N}\right)$ and longitude $\left(88^{\circ} 30^{\prime} \mathrm{E}\right.$ to $\left.\left.87^{\circ} 39^{\prime} \mathrm{E}\right)\right]$ were approached for participation in the study. The study was carried out on 34 adult Bengalee male food growers (age range 21-30 years) occupationally engaged in paddy cultivation. After obtaining necessary human ethical clearance, along with initial consents from the individuals, the names of volunteers were enlisted, and the procedural requirements were explained elaborately. Basic information regarding participants' age (year), working experience (year) and average working time (hr.day-1) recorded in a predesigned schedule. Socio-economic status (SES) was assessed by using Kuppuswamy's scale [25].

Stature $(\mathrm{cm})$ and body weight (BW) (kg) were measured using anthropometric measurement set and weighing scale respectively. Body mass index (BMI) was calculated from the measured stature (cm) and body weight (kg) data. The pre working heart rate (HR Prework) (beats. min-1), systolic and diastolic blood pressure (SBP Prework) and (DBP Pre-work) ( $\mathrm{mm} \mathrm{Hg}$ ) were recorded in the morning hours before the individuals started working using an automated blood pressure monitor in sitting condition. Waist circumference (cm) [26] and hip circumference (cm) [27] were measured by using non elastic tape. Conicity index (CI) [28], abdominal volume index (AVI) [29], Rohrer index (RI), hip adiposity index (HAI) [30-31] and a body shape index (ABSI) [31] were also obtained. Work related musculoskeletal discomfort was assessed by Cornell University's Musculoskeletal Discomfort Questionnaire (CMDQ) [32]. The obtained data were tabulated for statistical analysis. Obtained data were statistically analyzed. $\mathrm{P}$ value lower than $0.05(\mathrm{P}<0.05)$ was considered significant.

\section{Results and Discussions}

The basic profile including age (year), ethnic background, SES, working experience (year), average working time (hr.day-1) of the male food growers are presented in Table 1. The physical and physiological variables in terms of stature $(\mathrm{cm})$, body weight $(\mathrm{kg})$, HR Pre work (beats.min-1), SBP Pre work (mm Hg), and DBP Pre work ( $\mathrm{mm} \mathrm{Hg}$ ) have been presented in Table 2. Association between different obesity indices in terms of BMI, CI, RI, AVI, HAI and ABSI with CMDQ score have been presented in Figure 1.

Table 1: Basic profile of the study participants.

\begin{tabular}{|c|c|}
\hline Variables & Values \\
\hline Age (year) & $27.8 \pm 2.15$ \\
\hline Ethnic Background & Bengalee \\
\hline SES & Lower middle \\
\hline Working Experience (year) & $8.4 \pm 1.19$ \\
\hline${\text { Working time }\left(\text { hr.day }^{-1}\right)}$ & $6.9 \pm 1.05$ \\
\hline
\end{tabular}

$\mathrm{AM} \pm \mathrm{SD}$

Table 2: Physical and Physiological profile of the study participants.

\begin{tabular}{|c|c|}
\hline Variables & Values \\
\hline Stature $(\mathrm{cm})$ & $157.3 \pm 4.27$ \\
\hline BW $(\mathrm{kg})$ & $56.0 \pm 5.11$ \\
\hline HR Pre work (beats.min $\left.{ }^{-1}\right)$ & $72.0 \pm 3.26$ \\
\hline SBP Pre work (mm Hg) & $118 \pm 8.51$ \\
\hline DBP Pre work (mm Hg) & $78 \pm 8.11$ \\
\hline
\end{tabular}

$\mathrm{AM} \pm \mathrm{SD}$ 


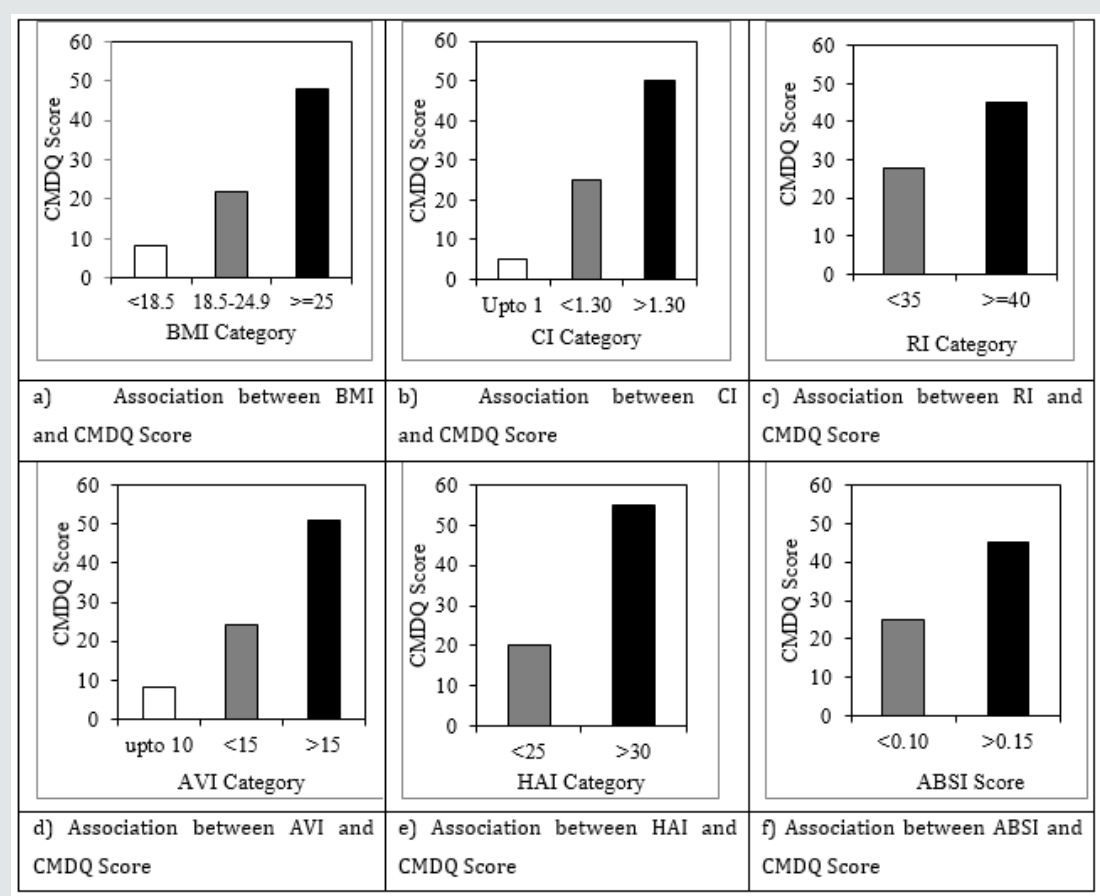

Figure 1: Association between different obesity indices and CMDQ score.

Obesity is a common condition and its prevalence is increasing worldwide [33-38] and our country is neither an exception [39-40]. It is characterized by excess body fat which is usually accompanied by increased total body mass. It is associated with numerous chronic health conditions, such as type 2 diabetes mellitus, cardiovascular disease, hypertension, and cancer. On the other hand, BMI is considered as one of the most popular indicator of obesity status [41]. In the present study, according to the BMI status of the participants, it was found that $12.9 \%$ of the participants were underweight, 35.5\% were within normal BMI range and 51.6\% of study participants (maximum percentage of subjects) were overweight as per WHO recommendation of BMI classification.

The main focus of the present study was to assess the musculoskeletal discomfort score and to find its association, if any, with the obesity indices among the study participants. CMDQ is a reliable and valid tool, for measurement of WMSD. Maximum CMDQ score has been found with individuals categorized as overweight followed by normal and underweight individuals. Significant association $(\mathrm{P}<0.01)$ existed between BMI and CMDQ scores (Figure 1) which is in agreement with earlier studies [3-4,22-23]. In the present study it is observed that, CMDQ score is significantly associated with CI $(\mathrm{P}<0.01)$, AVI $(\mathrm{P}<0.01)$, HAI $(\mathrm{P}<0.01)$ and ABSI $(\mathrm{P}<0.05)$, which is in agreement with other studies [7-10]. An earlier study [42] reported that, the risk of musculoskeletal pain among overweight/obese individuals was 1.7-times more as compared to individuals with normal body weight; especially increased BMI value which may be contribute to musculoskeletal discomforts [42].

Human resources working in front of a computer with high BMI were found to be more prone to WMSD, may be because overweight acts as a contributing factor in increasing the physiological and mechanical load on tissues. Relative disk pressure is being experienced during sitting with various inclinations of the back support. Intra-diskal pressure of the nucleus pulposus, acts as a load transducer and indicates the magnitude of axial loading on the spinal column and the increased pressure indicates a greater muscular effort in maintaining the posture and hence a larger stress on spinal column. Moreover, overweight yields a decreased postural stability and potentially negative impact on control of upper limb movements but its effect on control of balance imposes constraints on goal-directed movements. From a clinical perspective, obese individuals might be less efficient and more at risk of injuries than normal individuals in a large number of work tasks and daily activities especially requiring upper limb movements [43-44]. The result of the present study indicates positive association of obesity indices with MSDs among computer operators, occupationally engaged in organized sector and thereby reducing the performance level of the individual workers.

\section{Conclusion}

From the present study it may be concluded that that obesity indices are associated with musculoskeletal symptoms; and a rise in BMI, CI, AVI, HAI and ABSI increases the chance of MSD occurrence inhuman resources working with a computer in course of their regular occupationally engaged in paddy cultivating task. 


\section{Acknowledgement}

We are thankful to all volunteers for their participation.

\section{Conflicts of Interest}

Nil.

\section{References}

1. Chatterjee A, Chatterjee S, Banerjee N, Chatterjee S, Santra T, et al (2016) Seasonal Distribution of Thermal Comfort: A Study to Assess Physiological Strain in Male Paddy Cultivators in Southern Bengal. In: Proceedings of the International Conference on Humanizing Work and Work Environment (ISBN: 978-93-83006-81), 157-162.

2. Chatterjee A, Chatterjee S, Banerjee N, Chatterjee S, Santra T, et al. (2016) Assessment of Physiological Strain due to Work and Exposure to Heat of Working Environments in Male Paddy Cultivators. Advances in Applied Physiology 1(1): 8-11.

3. Goswami S, Pal A, Dhara PC (2012) Evaluation of Work-Related Musculoskeletal Disorder and Postural Stress among Female Cultivators Engaged in Post Harvesting tasks. Indian Journal of Biological Sciences 18: $16-25$.

4. Singh D, Vinay D (2014) Ergonomics Assessment of Traditional and Improved Methods of Paddy Threshing for Drudgery Reduction of Hill Region. Journal of Food, Agriculture and Environment 12: 244-250.

5. Chatterjee A, Chatterjee S, Chatterjee S, Santra T, Bhattacharjee S, et al. (2015) Exposure to Heat from Natural Working Environment and Cardiovascular Strain: A Study in Male Agricultural Workers in southern Bengal. In: Caring for People (ISBN 978-93-5258-836-7), 166-171.

6. Mohanty SK, Behera BK, Satapathy GC (2008) Ergonomics of Farm Women in Manual Paddy Threshing. Agricultural Engineering International: the CIGR E Journal 10: 1-14.

7. Kar SK, Ghosh S, Pal R, De S, Dhara PC (2012) Ergonomically Evaluation of Occupational Problems of Women Workers in Agricultural Tasks. International Journal of Basic and Applied Physiology 1: 103-108.

8. Ojha P, Kwatra S (2016) Development of MSD among the Farm Women Involved in Traditional and Mechanized Methods of Rice Cultivation of Northern India. Indian Journal of Traditional Knowledge 16: 162-166.

9. Chatterjee A, Chatterjee S, Chatterjee S, Santra T, Banerjee N, et al. (2015) Musculoskeletal Discomfort in Computer Operators of Organized Sector: Tracing the Link with Obesity Status. International Physiology (ISSN: 2347-1505), 3: 23-28.

10. Chatterjee A, Chatterjee S, Santra T, Mukherjee S (2014) The Influence of Anthropometric Variables for Development of Musculoskeletal Discomfort among Computer Operators in Organized Sectors. In: User Centered Design and Occupational Wellbeing, McGraw Hill Education (ISBN 978-93-392-1970-3), 499-503.

11. Chatterjee A, Chatterjee S, Chatterjee S, Santra T, Mukherjee S (2015) Musculoskeletal Discomfort in Computer Operators in Organized Sector. In: Proceedings of $22^{\text {nd }}$ West Bengal State Science and Technology Congress, MPH 12.

12. Chatterjee A, Chatterjee S, Chatterjee S, Bhattacharjee S, Banerjee N, et al. (2017) Workplace Heat Exposure and Cardiovascular Status: A Study in Male Paddy Cultivators. In: Molecular Physiological and Nutritional Responses during Pathological Alteration of Cell Function (ISBN: 8189169-33-5) 110-124.

13. Chatterjee A, Banerjee N, Chatterjee S, Santra T, Agrawal KM, et al. (2015) Assessment of Physiological Strain in Male Paddy Cultivators due to Work and Exposure to Fluctuation in Thermal Conditions in Working Environments. Survey (ISSN: 0586-0008) 55(3-4): 91-98.

14. Chatterjee A, Chatterjee S, Chatterjee S, Bhattacharjee S, Santra T, et al. (2018) Assessment of Physiological Strain in Male Cultivators Engaged in Mechanized Threshing Task Using Two Different Types of Threshers. Science and Culture (ISSN 0036 8156) 84(5-6): 191-197.

15. Chatterjee A, Chatterjee S, Chatterjee S, Banerjee N, Banerjee N, et al. (2018) Diurnal Variation in Thermal Working Environment, Workload and Physiological Strain in Women Workforces Engaged in Manual Parboiling Task. In: Advance Technologies in Agriculture for Doubling Farmers' Income (ISBN: 978-93-86453-61-7), New Delhi Publisher, India, 199-210.

16. Chatterjee A, Chatterjee S, Banerjee N, Santra T, Chatterjee S, et al. (2018) Assessment of Thermal Working Environmental Condition and Cardiac Response Indicators in Male Agricultural Workers Engaged in Traditional Manual Paddy Threshing Task. In: Technology Enabled Workplace Design (ISBN: 978-93-88237-27-7), Excel, India, 6.

17. Chatterjee A, Chatterjee S, Bhattacharjee S, Santra T, Banerjee N, et al. (2018) Assessment of Postural Discomfort in Male Paddy Cultivators in Southern Bengal. In: Technology Enabled Workplace Design (ISBN: 97893-88237-27-7), Excel, India, 7.

18. Chatterjee A, Chatterjee S, Banerjee N, Chatterjee S, Mukherjee S (2019) Climate Change and Human Performance: A Study in Bengalee Male Agricultural Workers. International Journal of Innovative Knowledge Concepts (ISSN: 2454-2415), 7 (Special Issue 1), 72-80.

19. Chatterjee A, Banerjee N, Chatterjee S, Chatterjee S, Mukherjee S (2019) A Study to Assess Cardiac Response Indices in Food Crop Cultivation Task in West Bengal. International Journal of Innovative Knowledge Concepts (ISSN: 2454-2415), 7: 238-243.

20. Chatterjee A, Banerjee N, Chatterjee S, Chatterjee S, Mukherjee S (2019) Impact of Variation in Working Environmental Condition on Cardiac Response Profile in Bengalee Male Crop Cultivators of a Southern District of West Bengal. Journal of Emerging Technologies and Innovative Research (ISSN: 2349-5162), 6(6): 438-443.

21. Chatterjee A, Chatterjee S, Banerjee N, Chatterjee S, Mukherjee S (2019) Assessment of Cardiac Strain in Male Paddy Cultivators Using Two Different Type of Paddy Thresher: A Comparison. Indian Agriculturist (ISSN: 0019-4336), 63, 49-55.

22. Chatterjee A, Chatterjee S, Chatterjee S, Banerjee N, Mukherjee S. (2018) A Comparative Study on the Impact of Thermal Working Environmental Factors and Workload on Cardiac Response Indicators in Male Food Crop Cultivators of Two Ethnic Groups. Indian Journal of Biological Sciences (ISSN 0972-8503), 24: 31- 44.

23. Chatterjee A, Chatterjee S, Banerjee N, Mukherjee S (2020) A Study to Assess Cardiac Response Profile in Paddy Cultivators Engaged in Manual Paddy Transplanting Task in Hooghly, West Bengal. NeBIO (ISSN 2278-2281(Online) I ISSN 0976-3597(Print), 11(1): 27-34.

24. Chatterjee A, Chatterjee S, Banerjee N, Mukherjee S (2020) Impact of Variation in Thermal Working Environmental Condition on Cardiac Response Indices in Male Human Resources Engaged in Food Crop Cultivation Task. Journal of Climate Change (ISSN (Print): 2395-7611, ISSN (Online): 2395-7697), 6(1): 59-66.

25. Ravikumar BP, Dudala SR, Rao AR (2013) Kuppuswamy's SocioEconomic Status Scale-A Revision of Economic Parameter for 2012. International Journal of Research and Development of Health 1(1): 2-4.

26. Hu G, Tuomilehto J, Silventoinen K, Barengo N, Jousilahti P (2004) Joint Effects of Physical Activity, Body Mass Index, Waist Circumference and Waist to Hip Ratio with the Risk of Cardiovascular Disease among Middle Aged Finnish Men and Women. Eur Heart J 25(24): 2212-2219.

27. WHO (2008) WHO Step Wise Approach to Surveillance (STEPS), Geneva: World Health Organization, USA.

28. Shidfar F, Alborzi F, Salehi M, Nojomi M (2012) Association of Waist Circumference, Body Mass Index and Conicity Index with Cardiovascular Risk Factors in Post-menopausal Women. Cardiovasc J Afr 23(8): 442445. 
29. Ezeukwu O, Agwubike EO (2014) Anthropometric Measures of Adiposity as Correlates of Atherogenic Index of Plasma in Non-Obese Sedentary Nigerian Males. Libyan J Med 9: 23798.

30. Pal A, Chatterjee S, De S, Sengupta P, Dhara PC (2014) Relationship between Obesity and CRF among Office Worker, Human Obesity from Viewpoint of Evolutionary Medicine. Health Consequences of Human Central Obesity 185-204.

31. Krakauer NY, Krakauer JC (2012) A New Body Shape Index Predicts Mortality Hazard Independently of Body Mass Index. PLoS One 7: e39504.

32. Hedge A, Marimoto S, McCrobie D (1999) Effect of Keyboard Tray Geometry on Upper Body Posture and Comfort with the Use of CMDQ (Cornell University Musculoskeletal Discomfort Questionnaire). Ergonomics 42(10): 1333-1349.

33. Banerjee N, Santra T, Chatterjee S, Mukherjee S (2015) Prevalence of Overweight in Rural Sedentary Human Resources in Southern Part of West Bengal. In: Ergonomics for Rural Development (ISBN 978-935174-905-9) 89-96.

34. Banerjee N, Chatterjee S, Chatterjee S, Ghosh K, De S, et al. (2015) Impact of Indian Traditional Recreational Activity on Novel Anthropometric Markers of Diabetes in Bengali Females. International Physiology (ISSN: 2347-1505) 3:11-15.

35. Mukherjee S, Banerjee N, Chatterjee S, Chatterjee S (2014) Effect of Practicing Select Indian Classical Dance Forms on Body Composition Status of Bengalee Females an Anthropometric Study. Indian Journal of Biological Sciences (ISSN 0972-8503) 18: 9-15.

36. Mukherjee S, Banerjee N, Chatterjee S, Chatterjee S (2014) Effect of Kathak Dancing on Obesity Indices in Women of Sedentary Avocations. Science and Culture (ISSN 0036 8156) 2014 80: 279-282.
37. Mukherjee S, Banerjee N, Chatterjee S, Chakraborti B (2013) Impact of Bharatnattyam Dancing Exercise on Reducing Central Obesity in Adult Bengalee Females. Science and Culture (ISSN 0036 8156) 79: 503-506.

38. Chatterjee A, Chatterjee S, Banerjee N, Santra T, Mondal P, et al. (2014) Evaluation of Body Composition and Somatic Profile in Male Individuals: A Comparison between Tribal and Non-Tribal Agricultural Human Resources. In: Proceedings of the National Conference on Agriculture and Rural Development Issues in Eastern India, ISI Giridih 25-26.

39. Chatterjee S, Banerjee N, Santra T, Chatterjee A, Chatterjee S, et al. (2014) Impact of Dancing on Obesity Indices on Bengalee Female Adolescents of Kolkata. American Journal of Sports Science and Medicine, 2: 40-44.

40. Mukherjee S, Banerjee N, Chatterjee S, Chatterjee S, Chatterjee A, et al. (2014) Effect of Bharatnatyam Dancing on Body Composition of Bengalee Female Children. American Journal of Sports Science and Medicine 2: 56-59.

41. Sethi J, Sandhu JS, Imbanathan I (2011) Effect of Body Mass Index on Work Related Musculoskeletal Discomfort and Occupational Stress of Computer Workers in a Developed Ergonomic Setup. Sports Medicine, Arthroscopy, Rehabilitation, Therapy and Technology 3: 1-7.

42. Shiri R, Solovieva S, Husgafvel PK, Taimela S, Saarikoski LA, et al. (2008) The Association between Obesity and Prevalence of Low Back Pain in Young Adults: The Cardiovascular Risk in Young Finns Study. Am J Epidemiol, 167: 1110-1119.

43. Viester L, Verhagen EALM, Oude Hengel KM, Koppes LL (2013) The Relation between Body Mass Index and Musculoskeletal Symptoms in the Working Population. BMC Musculoskeletal Disorders 14: 1-9.

44. Bihari V, Kesavachandran C, Pangtey BS, Srivastava AK, Mathur N (2011) Musculoskeletal Pain and its Associated Risk Factors in Residents of National Capital Region. Indian Journal of Occupational and Environmental Medicine 15: 59-63.

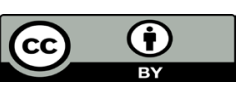

This work is licensed under Creative Commons Attribution 4.0 License

To Submit Your Article Click Here: Submit Article
DOI: 10.32474/OAJCAM.2020.02.000142

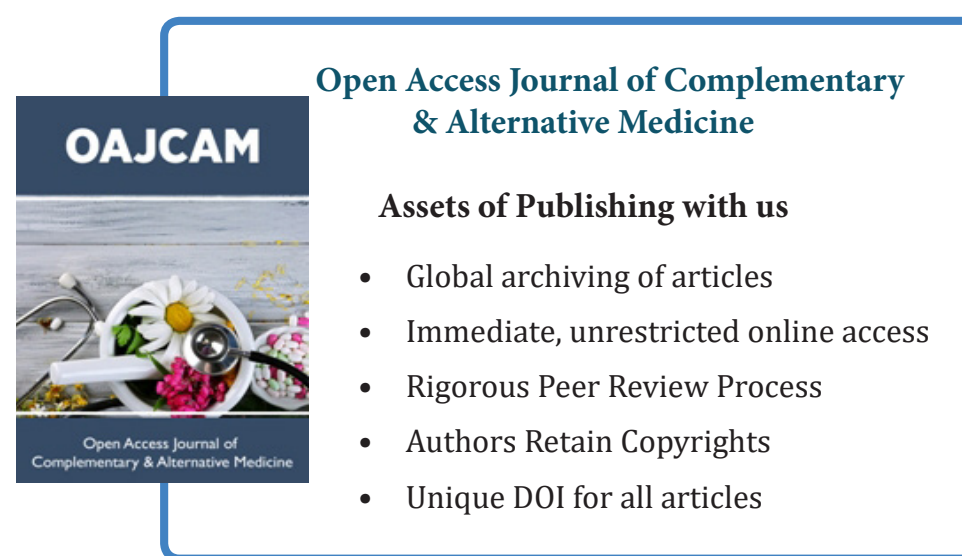

